\title{
Assessment and Management of Newly Diagnosed Classical Hodgkin Lymphoma: A Consensus Practice Statement from the Australasian Lymphoma Alliance
}

\author{
Cochrane $\mathrm{T}^{1,2}$, Campbell BA ${ }^{3,4}$, Gangatharan $\mathrm{SA}^{5,6}$, Latimer $\mathrm{M}^{7}$, Khor $\mathrm{R}^{8}$, Christie DRH ${ }^{9,10}$, Gilbertson \\ $M^{11,12,13}$, Ratnasingam $S^{14}$, Palfreyman $E^{15}$, Lee HP ${ }^{16}$, Trotman $\mathrm{J}^{17,18}$, Hertzberg $M^{19,20}$, Dickinson \\ $M^{21,22}$
}

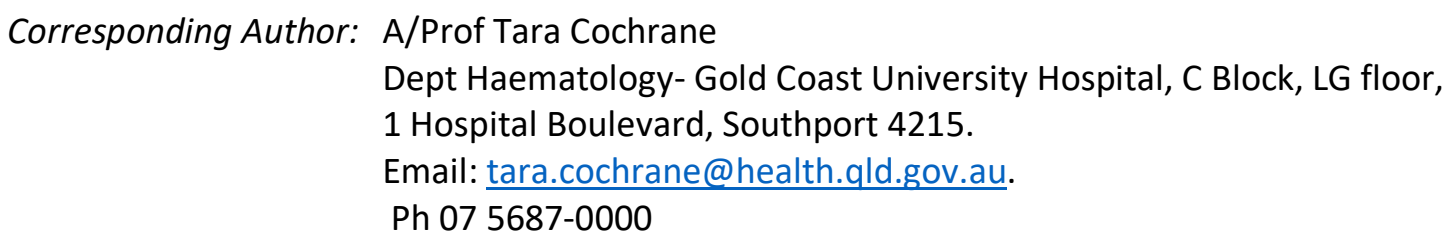

\section{Author Details \& Affiliations}

Tara Cochrane : BMBS, FRACP, FRCPA

1. Dept of Haematology, Gold Coast University Hospital, QLD

2. Griffiths University QLD

Belinda A Campbell MBBS, MMed, FRANZCR

3 Department of Radiation Oncology, Melbourne, Victoria.

4 Department of Clinical Pathology, University of Melbourne, Melbourne, Victoria.

Shane A Gangatharan MBBS, FRACP, FRCPA

5 Fiona Stanley Hospital, Perth, WA;

6 University of Western Australia, WA

Maya Latimer; MBBS, FRACP, FRCPA.

7 ACT Pathology and Canberra Hospital, ACT

Richard Khor FRANZCR

8 Austin Hospital, Melbourne, VIC

David Christie; MBChB, FRANZCR:

9 Genesiscare, Gold Coast, QLD

10 Bond University, Gold Coast, QLD

Michael Gilbertson; MBBS, FRACP, FRCPA;

11 Monash Health, Melbourne VIC

12 School of Clinical Sciences, Monash University, Melbourne, VIC

13 Dept of Haematology and Oncology, Western Health, Melbourne, VIC

Sumita Ratnasingam - MBBS, FRACP, FRCPA

14 Andrew Love Cancer Centre, University Hospital Geelong, Melbourne VIC

Emma Palfreyman MBBS (Hons), FRACP, FRCPA CCL (UIm);

15 Royal Darwin Hospital, NT

This article has been accepted for publication and undergone full peer review but has not been through the copyediting, typesetting, pagination and proofreading process which may lead to differences between this version and the Version of Record. Please cite this article as doi: 10.1111/imj.15503 
Hui-Peng Lee - MBChB, FRACP, FRCPA.

16 Flinders Medical Centre, Adelaide, SA

Judith Trotman MBchB, FRACP, FRCPA

17 Concord Repatriation General Hospital, Sydney, NSW

18 University of Sydney, Sydney, NSW

Mark Hertzberg, MBBBS, PhD FRACP FRCPA

19 Department of Haematology, Prince of Wales Hospital, Sydney, NSW

20 University of NSW, Sydney, NSW

Michael Dickinson; MBBS, FRACP, FRCAPA

21 Peter MacCallum Cancer Centre and Royal Melbourne Hospital, Melbourne, VIC

22 Sir Peter MacCalllum Department of Oncology, the University of Melbourne, VIC

\section{Author Contributions}

TC: coordinated the project, drafted, revised, critically reviewed and edited the work.

BAC, MD : drafted, revised, reviewed and edited the work

SAG, ML, RK, DC, MG, SR, EP, HPL: drafted and reviewed the work.

$\mathrm{JT}, \mathrm{MH}$ : critically reviewed and edited the work

All authors contributed to the design of the work, approved the final version and are accountable for all aspects of the work

\section{Conflict of Interest}

TC: Honoraria - Celgene

SAG: Received conference registration funding from AstraZeneca, and Roche. Advisory board for AstraZeneca

MJD: Advisory boards for MSD and Takeda, Research Funding from MSD.

The other authors declare no conflict of interest.

\section{$\underline{\text { Word count }}$}

Abstract- 90

Main Document: 3480

\section{ABSTRACT}


The management of Hodgkin Lymphoma $(\mathrm{HL})$ has undergone significant changes in recent years. Due to the predilection of $\mathrm{HL}$ to affect younger patients, balancing cure and treatment related morbidity is a constant source of concern, for physicians and patients alike. PET adapted therapy has been developed for both early and advanced stage HL to try and improve the outcome of treatment, whilst minimising toxicities. The aim of this review is to digest the plethora of studies recently conducted and provide some clear, evidence-based practice statements to simplify the management HL.

\section{$\underline{\text { Key Words }}$}

Hodgkin Lymphoma, PET adapted, chemotherapy, HL, radiotherapy.

\section{Abbreviations}

ABVD - doxorubicin / bleomycin / vinblastine / dacarbazine

ALA - Australasian Lymphoma Alliance

ASHL - advanced stage Hodgkin lymphoma

eBEACOPP - escalated bleomycin/ etoposide / doxorubicin / cyclophosphamide / vincristine / procarbazine / prednisone

BV - brentuximab vedotin

CHL - classical Hodgkin lymphoma

ChIVPP - chlorambucil / vinblastine / procarbazine / prednisolone

CHOP - cyclophosphamide /doxorubicin / vincristine / prednisone

CMT - combined modality therapy

DS - Deauville score

EOCT - end of chemotherapy

EORTC - European Organisation for Research and Treatment of Cancer

ESHL- early stage Hodgkin lymphoma

ESHL-F - early stage favourable Hodgkin Lymphoma

ESHL-U - early stage unfavourable Hodgkin lymphoma

FDG - fluorodeoxyglucose

FFS - failure free survival

GHSG - German Hodgkin Study Group 
Gy - Gray

HL - Hodgkin lymphoma

HRS - Hodgkin Reed Sternberg

ILROG - International Lymphoma Radiation Oncology Group

INRT - involved node radiotherapy

IPS - international prognostic score

ISRT - involved site radiotherapy

NLPHL - nodular lymphocyte predominant Hodgkin lymphoma

OS - overall survival

PET - positron emission tomography

iPET2 - interim PET scan conducted after 2 cycles of chemotherapy

PFS - progression free survival

PVAG - prednisone / vinblastine / doxorubicin / gemcitabine

$\mathrm{RT}$ - radiation therapy

$\mathrm{SMN}$ - second malignant neoplasms

TGA - Therapeutic Goods Administration

TRM - treatment related mortality 


\section{Assessment and Management of Newly Diagnosed Classical Hodgkin Lymphoma: A Consensus Practice Statement from the Australasian Lymphoma Alliance}

\section{INTRODUCTION}

Hodgkin Lymphoma $(\mathrm{HL})$ is a lymphoid malignancy of B-cell origin. Classical $\mathrm{HL}(\mathrm{CHL})$, accounting for 90-95\% of cases, is the focus of this paper.(1) Nodular Lymphocyte Predominant HL (NLPHL) comprises the remaining $5-10 \%$. In Australia, the annual incidence of HL is approximately 2.42.9/100,000 (500-600 cases/year).(2) CHL incidence has a bimodal age distribution, with a peak in patients aged $15-30$ and a second peak in patients $>50$ years. With an imperative to maximise cure while minimising long-term toxicity, a $\mathrm{HL}$ diagnosis in young adulthood brings additional implications for fertility, and patient engagement in therapeutic decision-making is required.

\section{METHODOLOGY}

This consensus practice statement was undertaken by a panel of lymphoma experts with particular interest in HL under the auspices of the Australasian Lymphoma Alliance (ALA) in accordance with the ALA policy for Consensus Practice Statement development (Supplementary material).

\section{DIAGNOSIS}

The diagnostic, malignant HRS (Hodgkin Reed-Sternberg) cells comprise only a minority of cells in the tumour, with the bulk of the cellular infiltrate being a rich milieu of inflammatory cells and sometimes regions of fibrous sclerosis. Excisional biopsy is preferred, however, a good quality core biopsy may suffice. Classic HRS are derived from germinal centre B-lymphocytes crippled during maturation. Typical immunohistochemistry for HRS cells are CD30+/CD15+/CD45-; the B cell antigens CD20/C79a are frequently negative, however PAX5 is demonstrable in most cases.(1) The histological pattern of the surrounding inflammatory infiltrate further subtypes $\mathrm{CHL}$ into four histological variants: i) nodular

This article is protected by copvright. All rights reserved. 
sclerosis ii) mixed cellularity iii) lymphocyte rich iv) lymphocyte deplete.(1) These subtypes do not impact on treatment selection.

\section{CLINICAL FEATURES}

Contiguous nodal spread is typical. Most patients present with cervical and mediastinal lymphadenopathy. Isolated infra-diaphragmatic disease, seen in $10 \%$ of patients, is more common in older individuals. Constitutional ("B") symptoms defined as unexplained pyrexia $\left(>38^{\circ} \mathrm{C}\right.$ ), drenching night sweats in the previous month, or significant ( $>10 \%$ in 6-months) weight loss, occur in $40 \%$ of patients. Pruritis and chest pain following alcohol consumption are described. Bone marrow involvement occurs in the minority $(<10 \%)$ of cases .(3)

\section{Recommendation}

\section{- Diagnostic Work-up as per Table 1.[I,A]}

\section{STAGING AND RISK STRATIFICATION}

Staging is according to the modified Ann Arbor classification (Table 2).(3) Early-stage HL (ESHL) is risk stratified into favourable (ESHL-F) and unfavourable (ESHL-U) risk groups, with notable differences between the German Hodgkin Study Group (GHSG) and the European Organisation for Research and Treatment of Cancer (EORTC)(Table 3).(4) Lymph node areas used in these definitions differ from lymph node regions in the Ann Arbor classification (supplementary table 1). Advanced stage HL (ASHL) includes stage III/IV disease and in the GHSG classification, stage IIB disease with bulk or extranodal disease. The International Prognostic Score (IPS)(5) is a tool to further risk-stratify ASHL (Table 4), however, there are no published trials that determine management by IPS score.

\section{FDG PET in staging and response assessments}

18F-fluordeoxyglucose (FDG) positron emission tomography (PET) scan is the modality of choice for initial staging and response assessments in HL. FDG-PET scans are visually scored using a 5-point scale relating FDG-PET avidity to mediastinal and liver blood pool. (Deauville Score [DS]- supplementary 
table 2) FDG-PET is an integral component of response adapted therapy. Interim FDG-PET scans (iPET) are generally conducted after 2 cycles of therapy (iPET2). Trial definitions may differ when defining the cut-off for negative iPET; some use $\leq$ DS2,(6-8) others use $\leq$ DS3(9). A negative end of chemotherapy (EOCT) FDG-PET scan, consistently defined as $\leq D S 3$, is considered a complete remission. A positive EOCT-PET scan requires further investigation as differentiating residual HL from benign causes of FDG avidity can be difficult; when biopsy is not practical, serial FDG-PET may be considered.

\section{Recommendations}

- Accurate staging and risk stratification must be documented in all patients with HL.[I,A]

- $\quad$ PET is the preferred modality for staging and response assessment.[I,A]

\section{MANAGEMENT}

\section{Principles of Radiation Therapy (RT)}

The goal of RT within a multi-modality approach is to optimise local control. Over time, RT doses and volumes have dramatically reduced as the understanding of radiation-induced carcinogenesis and late effects has evolved. Improvements in systemic therapy efficacy and RT technologies have allowed target volumes to reduce from historical total nodal irradiation,(10) to modern involved node (INRT) or involved site (ISRT) radiotherapy, with excellent cure rates maintained.(11) Of note, INRT and ISRT are critically dependent on the adequacy of pre-chemotherapy imaging. The smaller INRT volume may be considered a "special case of ISRT" when there is optimal pre-chemotherapy imaging: localising initial disease sites on pre-chemotherapy PET/CT acquired with the patient in the RT treatment position. Technical RT guidelines are published by the International Lymphoma Radiation Oncology Group (ILROG).(12) 


\section{Principles of Chemotherapy}

ABVD is commonly used (Table 5). Maintaining dose intensity is important, and ABVD does not require G-CSF as primary prophylaxis, even with grade 4 neutropenia.(13) Monitoring of respiratory symptoms is required with bleomycin, with omission of bleomycin advisable if new respiratory symptoms develop. Bleomycin must be used with caution in patients $>60$ years.

Escalated BEACOPP (Table 5 ) is an intensive regimen, reserved for patients $<60$ years. For patients aged 40-59 years, caution is advised due to the increase in treatment-related mortality (TRM); the GHSG recommends hospital admission in cycle 1 for the neutropenic phase.(14) Dose reductions may be required according to toxicities(15) and prophylactic medications (filgrastim, pneumocystis jirovecii and antiviral prophylaxis are recommended).

\section{Early-stage Favourable HL (ESHL-F)}

ESHL-F accounts for approximately $45 \%$ of ESHL.(16) Following first-line therapy, 5 -year OS is $>90 \%$.(17) Chemotherapy plus consolidation RT (combined modality therapy, CMT) is the current standard of care.(18) For patients with ESHL-F according to GHSG criteria, 2 cycles of ABVD (ABVDx2) followed by 20Gy RT, is acceptable. The GHSG HD10 randomised trial (19) of 1190 patients confirmed that treatment intensity could be safely reduced from 4 cycles of ABVD to 2 , and $30 \mathrm{~Gy}$ of RT to $20 \mathrm{~Gy}$. Three PET-adapted trials in ESHL-F have confirmed the benefit of CMT. RAPID (8) and EORTC $\mathrm{H} 10$ (7)used 3 cycles of ABVD plus RT as the standard arm, and randomised patients with negative iPET ( $\leq \mathrm{DS} 2$ ) to CMT versus ABVD alone (3 or 4 cycles). GHSG HD16 (6) attempted to omit RT in patients with a negative PET after ABVDx2. All 3 trials revealed increased rates of progression (by 7-12\%) with chemotherapy alone.

iPET has utility for PET-adjusted intensification of therapy. EORTC H10 (7) demonstrated superior outcomes in a combined analysis with ESHL-U when therapy was changed to eBEACOPP for 2 cycles (eBEACOPPX2) plus RT in patients with positive iPET2 ( $\geq \mathrm{DS} 3$ ). If escalation to eBEACOPP is not 
possible, good outcomes are still achievable (8), with $87 \%$ PFS for patients with positive iPET3 receiving total ABVDx4 plus 30Gy RT, at median 62 months follow-up.

\section{Recommendations}

- CMT consisting of abbreviated ABVD plus RT is the standard of care.[I,A]

$\circ 2$ cycles ABVD and 20Gy RT for patients who fit GHSG favourable criteria.[II,A]

OR

- 3 cycles of ABVD and 30Gy RT.[II,A]

- Positive iPET post 2 cycles of ABVD identifies patients at higher risk of treatment failure:

- Treatment escalation with 2 cycles eBEACOPP followed by 30 Gy RT is preferred.[II,A]

OR

- 4 total cycles of ABVD plus RT may be used, if escalation to BEACOPP is inappropriate.[II,A]

- No clear risk-group has been identified in whom RT might be omitted without potential detriment in PFS. $[I, A]$. RT omission may be considered if the radiotherapy field exposes the patient to unacceptably high risk of long-term toxicity (as determined by a radiation oncologist). In this context, no fewer than 3 cycles of ABVD should be delivered.

\section{Early-stage Unfavourable HL (ESHL-U)}

ESHL-U accounts for approximately 55\% of ESHL. Five-year patient outcomes on contemporaneous protocols are $90-95 \%$ PFS and $95 \%$ OS. $(7,20)$ The standard CMT used to benchmark other therapeutic strategies is 4 cycles of ABVD plus 30Gy RT.(18) 
GHSG HD14 (20) randomised patients with ESHL-U to ABVDx4 plus 30Gy RT, or eBEACOPPx2 then ABVDx2 (so-called "2+2") plus 30Gy RT. Patients who received "2+2" plus RT had improved 5-year PFS: 95.4\% versus $89.1 \%,(P<0.001)$. The improved 10 -year PFS of " $2+2$ " regimen $(91.2 \%$ versus $85.6 \%$; $P<$ 0.0001) was confirmed, without differences in OS or secondary malignancies.(21)

In the ESHL-U cohort of EORTC-H10,(7) a PET-adapted approach was compared to ABVDx4 plus 30Gy RT. In the PET-adapted arm, patients with negative iPET2 ( $\leq D S 2)$ received additional ABVDx4 alone (total, 6 cycles ABVD). Of the 594 patients who were iPET2 negative, those who received CMT had a 92.1\% 5-year PFS, versus $89.6 \%$ in the ABVD-alone arm. The criteria for non-inferiority was not met, and CMT remains the standard of care for patients with negative iPET2 after ABVDx2. Patients with positive iPET2 ( $\geq D S 3$ ) after ABVDx2 in EORTC-H10 either received 2 further cycles of ABVD plus 30Gy RT (standard arm) or received eBEACOPPx2 plus 30Gy RT (experimental arm). The intensification to eBEACOPP was associated with improved 5-year PFS: $90.6 \%$ versus $77.4 \%(P=0.02) .(7)$

GHSG HD17(22) has demonstrated that FDG-PET may identify patients in whom RT may be omitted following intensified initial chemotherapy using the " $2+2$ " regimen. In the PET-adapted arm, patients with negative EOCT-PET ( $\leq \mathrm{DS} 2$ ) did not receive RT; this PET-guided approach was non-inferior to CMT (5-year PFS of $95.9 \%$ for no RT versus $97.7 \%$ for CMT). A greater risk for treatment failure (5-yr PFS 81.6\%) is evident if EOCT-PET is DS $\geq 4$.

A chemotherapy-only approach may be considered for patients in whom CMT is not appropriate due to the high risk of radiation-induced toxicity, as determined by a radiation oncologist.

\section{Recommendations}

\section{- CMT using 4 cycles of ABVD followed by $30 \mathrm{~Gy} R T$ is an accepted standard.[I,A]}


- The $2+2$ regimen (eBEACOPP $\times 2+$ ABVD $\times 2$ ) is another accepted standard chemotherapy regimen and PET directed omission of RT may be considered in patients treated with the $2+2$ regimen if the EOCT PET is negative. [II,A]

- A positive iPET after 2 cycles of ABVD identifies patients at higher risk of treatment failure. Treatment escalation with eBEACOPP $\times 2$ followed by $30 \mathrm{~Gy}$ RT is preferred.[II,A] Completing 4 cycles of ABVD and RT(18) should be considered where escalation to eBEACOPP is not appropriate.

- A chemotherapy-alone strategy may be considered for patients at high risk of RT-induced complications. Options include:

- "2+2" regimen, if EOCT-PET is negative.[II,A]

ABVD x2 then iPET directed

If iPET2 is negative, complete either ABVD $\times 4$ or AVD x4.[II,A]

$O$ If iPET2 is positive consider changing to eBEACOPP $x 4$ (in young, fit patients).[III-3,B]

\section{Advanced stage HL (ASHL)}

ASHL is typically managed with chemotherapy alone. Six cycles of ABVD (ABVDx6) achieves 5-year FFS of $61-85 \%$ and OS of $73-87 \%(23)$ and remains a standard against which new therapies are compared. Escalated BEACOPP for 6 cycles yields improved PFS and OS relative to ABVD in patients $<60$ years,(24) but comes with increased short and long-term toxicities. Interim PET-stratified approaches have been evaluated in an attempt to select the patients most likely to benefit from an intensified approach.

Patients with negative iPET2 after ABVDx2 may have bleomycin safely omitted for subsequent cycles. In the RATHL study(9) of 1200 patients with stage IIA-IVB HL (58\% had stage III/IV), the omission of 
bleomycin did not adversely impact survival: patients with negative iPET2 scans ( $\leq D S 3)$ were randomised to 4 further cycles of ABVD versus AVD: 3-year PFS was $85.4 \%$ and $84.0 \%$, respectively, with non-inferiority demonstrated.(25) Treatment escalation to eBEACOPP for those with positive iPET2 scans resulted in 3-year PFS of 68\%(9). Compared to historical controls of ABVD alone $(26,27)$, this approach may have a PFS benefit, however, head-to-head studies are lacking.

In patients with negative iPET2 following 2 cycles eBEACOPP, treatment may be de-escalated from 6 cycles of eBEACOPP to 4 cycles, with improved safety profile. In GHSG HD18,(28) patients with ASHL (stage IIB-IVB) were commenced on eBEACOPP, and those who were iPET2 negative (SDS2) were randomised to 2 versus 4 additional cycles of eBEACOPP. In the recent 5-year update(29) among iPETnegative patients, a total of 4 cycles of eBEACOPP was found to be non-inferior to 6 cycles of eBEACOPP (5-year PFS, 91.0\% versus $90.9 \%$, respectively).(29) A post-hoc analysis found equivalent 3yr PFS rates for patients with DS3 and DS1-2 on iPET2; hence, GSHG HD21 uses DS $\leq 3$ to define a negative iPET2.(30)

In patients with negative iPET2 following 2 cycles of eBEACOPP, de-escalation to ABVD to complete a total of 6 cycles of treatment, delivers comparable survival outcomes to 6 cycles of eBEACOPP. In the AHL2011 study,(31) 800 patients with stage IIB-IVB HL commenced eBEACOPP, with iPET2 performed after cycle 2. Patients assigned the standard arm received a further 4 cycles of eBEACOPP, those in the experimental arm were de-escalated to 4 cycles of ABVD if iPET2 was negative ( $\leq D S 3)$. AHL2011 demonstrated that de-escalating to ABVD did not compromise outcome, (5-year PFS 86.2\% versus $85.7 \%$ respectively).

Brentuximab vedotin (BV) combined with AVD (A-AVD) has been compared to ABVD chemotherapy in untreated ASHL(32) and resulted in a 7\% improvement in 3-year PFS (83\% versus 76\%)(33); patients with higher risk disease (stage IV, IPS score 4-7 and extra-nodal disease) appeared to have greater benefit from A-AVD. Notably, there were greater incidences of peripheral neuropathy and neutropenia with A-AVD. Currently, BV is not TGA approved for treatment of untreated ASHL. 
Conventionally, consolidation RT has been considered for patients with ASHL with bulky disease or incomplete response. The role of PET-directed consolidative RT at the end of chemotherapy has been difficult to evaluate in randomised studies due to issues of power and feasibility. Data supports the omission of RT after eBEACOPP if the EOCT-PET scan is negative.(34) HD607(35) randomised 296 patients treated with ABVD with negative $\mathrm{PET}$ and EOCT-PET to consolidation RT versus observation. There was no difference in 6-year PFS, and pre-subgroup analyses did not detect differences in outcomes based on baseline bulk.

\section{Recommendations}

- $\quad$ PET-adapted treatment is preferred for fit patients aged $<60$ years. [I,A]

- PET-adapted strategies include:

- ABVDx2, escalating to eBEACOPP if $\mathrm{iPET} 2$ is positive [III-3, B], or continuing with AVD if iPET2 is negative.[II,A]

O eBEACOPPX2, continuing to 4 instead of 6 cycles of eBEACOPP if iPET2 is negative.[II,A]

- eBEACOPPx2, de-escalating to additional ABVDx4 if iPET2 is negative.[II,A]

- If a PET-adapted approach is not possible, acceptable alternatives are ABVD x6 or 6 cycles of eBEACOPP.[I,A]

- RT may be omitted if EOCT-PET is negative after EBEACOPP and if iPET and EOCT-PET are negative when ABVD is used.[II-III,A]

- If EOCT-PET is positive at sites of the original HL, RT should be considered if FDG-avid residual disease is $\geq 2.5 \mathrm{~cm}$ and is safely encompassable within the RT field. $*[\mathrm{III}-2, \mathrm{~B}]$

*If there is concern of disease progression on the EOCT-PET, consider a repeat biopsy and manage as refractory $\mathrm{HL}$. 


\section{Elderly HL patients}

In the context of $\mathrm{HL}$, elderly is defined as $>60$ years. Older patients are more likely to have mixed cellularity histology, stage III/IV disease, infra-diaphragmatic presentation, less bulk, and higher incidence of B-symptoms.(36)

Tolerance to ABVD is compromised in older patients. Increased incidence of bleomycin toxicity during ABVD is reported (5-36\%), with treatment-related mortality (TRM) approaching 25\%.(37) Bleomycin lung toxicity rates increase when patients receive $>2$ cycles of ABVD. $(38,39)$ Even with bleomycin omitted, grade 3-4 adverse events were $40 \%$ in the AVD arm of GHSG HD13 trial.(39) There is no role for treatment escalation (e.g. eBEACOPP) due to unacceptably high TRM.(36)

Many studies in ESHL included patients up to $70-75$ years. $(6-8,19,40)$ Thus, in fit patients aged $\leq 75$ with ESHL a reasonable option would be 2-4 cycles of $A(B) V D$ (depending on risk factors) plus RT.

The management of ASHL in older patients is challenging, with notable under-representation in clinical trials. $(9,23)$ Attempts to use a tolerable, yet effective, chemotherapy regimen for older patients have not demonstrated a clear advantage of one regimen over the other. $(41,42)$ If co-morbidities allow, an anthracycline-based regimen is preferred. (36)

For very frail patients, better-tolerated regimens such as ChIVPP(15) are available, but have inferior outcomes. Careful assessment of frailty and discussion around treatment goals are necessary prior to starting therapy.

\section{Recommendations}

- Treatment strategies for ESHL in the fit elderly group (61-75 years) are in line with prior sections for younger patients; 2-4 cycles of A(B)VD, followed by RT.[I,A] 
- The treatment strategy for ASHL is 6 cycles of chemotherapy.[I,A]

- Anthracycline-based chemotherapy should be used where possible in older patients with HL. Consider A(B)VD or CHOP(42)or PVAG(41).[III-3,B-C]

- Bleomycin must be used with caution in patients $>60$ years, and if used, should be limited to 2 cycles.[III-2,B-C]

- eBEACOPP should not be used in patients $>60$ years.[II,A]

\section{SURVEILLANCE OF LATE EFFECTS}

Long-term survivors of $\mathrm{HL}$ are at risk of late treatment-induced toxicities. (supplementary table 3) These include second malignant neoplasms, cardiovascular and pulmonary toxicity, endocrinopathies and infertility. Secondary malignancy, cardiovascular and pulmonary deaths constitute the leading causes of non-HL mortality.(43-46) Long-term surveillance is recommended and should commence 5 years after completion of treatment.(47) Primary prevention and risk minimisation strategies are strongly encouraged.

\section{Second malignant neoplasms (SMN)}

Although solid cancers account for most SMN in HL survivors, the standardised incidence ratio for haematological malignancies is greater: 4.2 for solid cancer versus 10.4 for haematological malignancy.(48) An increased risk of solid tumours begins approximately 5 years after therapy and continues to rise for $>30$ years,(49) whereas the risk for secondary haematological malignancies is greatest in the first 10 years.(50) Incidence and relative risk of death from SMN are associated with younger age at treatment. $(43,48)$ Of note, reported incidences of morbidity and mortality of SMN are largely derived from historical regimens and may not reflect contemporary protocols or techniques. 
The risk of secondary breast cancer is greatest in female patients receiving supradiaphragmatic, "mantle" extended-field RT and aged $<30$ years at the time of RT. Alkylator exposure and/or pelvic RT are protective, putatively through ablative effects on ovarian function. $(48,51-54)$ Higher RT doses (52) and large volumes(55) increase the risk, which may be up to 32-fold using historical doses and fields.(56) With contemporary RT techniques,_secondary breast cancer rates have substantially reduced,(57) with one report suggesting CMT may not confer any greater risk of breast cancer relative to chemotherapy alone.(58)

Therapy-related myeloid neoplasms are well recognised risks in long-term survivors of $\mathrm{HL}$, and typically have a poor prognosis. $(59,60)$ Alkylating agents and topoisomerase II inhibitors are leukemogenic; regimens using these agents may result in a greater risk relative to ABVD. $(24,59)$ There is also thought to be an effect from combined exposure to both alkylators and RT.

Patients receiving neck RT are at risk of thyroid neoplasms(61) RT-induced thyroid cancer risk is dosedependent: reportedly up to 14.6 -fold greater after <20Gy, $(46,54)$ whereas doses >20Gy may produce lower risk due to the cytocidal effect of RT on radio-sensitive thyroid tissue. $(46,54)$ Other risk factors include female sex, age $<10$ years at the time of RT, and longer time since treatment.(46)

Smokers with exposure to thoracic RT are at the greatest risk of lung cancer,(62) with a multiplicative effect observed.(56) The risk of secondary lung cancer is also increased in patients with exposure to alkylating agents (particularly procarbazine), even in the absence of thoracic RT.(48)

\section{$\underline{\text { Late Organ toxicities }}$}

Patients with prior exposure to anthracyclines and/or mediastinal RT have lifelong risks of cardiac sequelae. Treatment-induced cardiotoxicities are dose-related, and include cardiomyopathies, coronary artery disease, arrhythmias, valvular, and pericardial disease. $(63,64)$ 
Bleomycin exposure(65) and thoracic RT are known causes of pulmonary toxicity. Risks for late lung fibrosis are dose-related, and greater in patients with acute treatment-induced pneumonitis or preexisting interstitial lung disease.

Endocrinopathies are common late toxicities. Hypothyroidism-risk following neck RT is dosedependent, and those at younger age at time of RT.(66) Rates of hypothyroidism are inversely proportional to time since treatment, but remain elevated for $>25$ years.(66) Risks of RT-induced hyperthyroidism are dose-dependent, with the radiation-related excess risk also persisting for >25 years.(67) Chemotherapy-induced hypothyroidism can be seen following bleomycin and cyclophosphamide(66). Premature gonadal insufficiency and infertility are associated with alkylating chemotherapy agents and/or pelvic RT. These risks are age-related in both sexes, with higher rates of toxicity observed in patients aged $>30$ at the time of therapy.(68) Although ABVD is considered to be lower risk, transient azoospermia can occur, but usually recovers by 2 years. Bone density loss can ensue following premature gonadal insufficiency, steroid or alkylating agent use.

\section{Recommendations}

\section{- Surveillance of late effects are outlined in supplementary table 3 [IV,A]}

\section{SUMMARY AND CONCLUSIONS}

The diagnosis, workup and management of $\mathrm{HL}$ presents unique challenges. Evidence-based options are now available for all stages of $\mathrm{HL}$, accommodating patients 'values and priorities. The informed consent process for therapy, particularly in young patients, requires detailed discussion of the pros and cons of each approach. Ideally, all patients with newly diagnosed HL should be discussed at a multi-disciplinary team (MDT) meeting including specialists in pathology, radiology, nuclear medicine, haematology and radiation oncology. Physicians concerns about the increased risks of intensive 
therapies may be partially addressed through recent data on iPET driven approaches. Although Programmed-Death-1 inhibitors and BV have a clear role in relapsed/refractory $\mathrm{HL}$, there is presently no convincing data to justify routine use in the front-line setting. An important goal of newer regimens is to improve upon outcomes achieved by ABVD and eBEACOPP in higher risk $\mathrm{HL}$, including reduction in both short and long-term toxicities. 


\section{$\underline{\text { TABLES }}$}

Table Legend:

\section{TABLE 1: Diagnostic Workup}

*As per Cheson (3), staging should involve a PET-CT, where the CT component is low dose. A contrastenhanced CT (either done at the same time at the PET-CT or at another time) is favoured as it provides superior characterisation of disease extent, if radiotherapy is planned.

\# Full Biochemistry-included electrolytes, urea, creatinine, liver function test, lactate dehydrogenase.

\section{TABLE 2: Ann Arbor staging with Cotswold's modification}

*Bulk is defined as a single nodal mass of at least $10 \mathrm{~cm}$, or greater than a third of the transthoracic diameter.

** Lymph nodes, spleen, Waldeyer's ring and thymus are considered nodal sites, with others defined as extra-nodal(3)

\section{$\underline{\text { TABLE 3: Staging and Risk Factors }}$}

\section{TABLE 4: International Prognostic Score - adverse risk factors}

Each factor present is given 1 point. Score is out of 7

\section{TABLE 5: Chemotherapy Regimens}

*A corticosteroid pre-phase should be considered prior to commencing eBEACOPP in patients $>40$ years. 
TABLE 1: Diagnostic Workup

\begin{tabular}{|c|c|c|c|}
\hline & $\begin{array}{l}\text { Diagnostic } \\
\text { Investigation }\end{array}$ & Rationale for Test & Comment \\
\hline Histopathology & $\begin{array}{l}\text { core or excision biopsy } \\
\text { of a PET avid lesion }\end{array}$ & For diagnosis & \\
\hline Bloods & $\begin{array}{c}\text { FBE } \\
\text { \#Full Biochemistry } \\
\text { ESR } \\
\text { Hep B/C/HIV serology } \\
\text { beta HCG }\end{array}$ & $\begin{array}{l}\text { Pre-Treatment Assessment } \\
\text { Pre-Treatment Assessment } \\
\text { Risk Stratification } \\
\text { Pre-Treatment Assessment } \\
\text { Pre-Treatment Assessment }\end{array}$ & 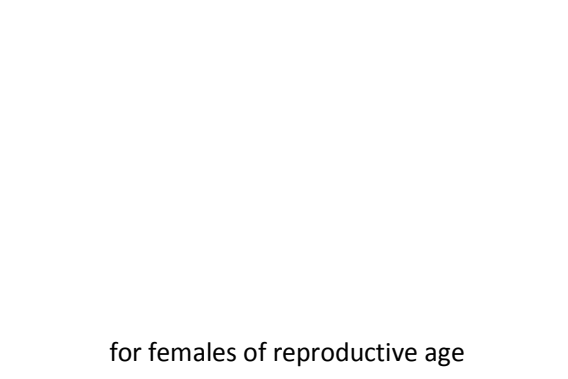 \\
\hline Imaging & $\begin{array}{l}\text { PET-CT with full } \\
\text { contrast-enhanced } \mathrm{CT}^{*} \\
\text { CXR }\end{array}$ & $\begin{array}{l}\text { Staging, Risk Stratification and for } \\
\text { subsequent response assessment } \\
\text { Staging and Risk Stratification }\end{array}$ & $\begin{array}{l}\text { A separate contrast-enhanced CT is not required } \\
\text { provided the initial PET scan included a contrast- } \\
\text { enhanced CT. }\end{array}$ \\
\hline Bone Marrow & $\begin{array}{l}\text { Bone Marrow Aspirate } \\
\text { and Trephine }\end{array}$ & $\begin{array}{l}\text { Not recommended if PET-CT } \\
\text { done. Consider performing if } \\
\text { there are unexplained cytopenias }\end{array}$ & $\begin{array}{l}\text { Homogenous uptake is likely reactive, consider } \\
\text { bone marrow involvement if there is focal or } \\
\text { multifocal avidity on PET scan. }\end{array}$ \\
\hline $\begin{array}{l}\text { Functional Organ } \\
\text { Assessment }\end{array}$ & $\begin{array}{l}\text { Cardiac Assessment } \\
\text { (MUGA or Echo) } \\
\text { Pulmonary Function }\end{array}$ & $\begin{array}{l}\text { Pre- Rx Assessment } \\
\text { Pre-Rx Assessment and for } \\
\text { subsequent comparisons }\end{array}$ & Ensure DLCO is examined. \\
\hline Other & $\begin{array}{l}\text { Reproductive } \\
\text { Counselling and Fertility } \\
\text { Preservation }\end{array}$ & $\begin{array}{l}\text { To consider sperm / oocyte / } \\
\text { embryo / ovarian tissue } \\
\text { preservation pre-treatment } \\
\text { where feasible }\end{array}$ & $\begin{array}{l}\text { Referral to a Reproductive Specialist particularly } \\
\text { for female patients who wish to preserve their } \\
\text { fertility must be done expediently }\end{array}$ \\
\hline
\end{tabular}

*As per Lugano 2014(3), staging should involve a PET-CT, where the CT component is low dose. A contrast-enhanced CT (either done at the same time at the PET-CT or at another time) is favoured as it provides superior characterisation of disease extent, if radiotherapy is planned.

\# Full Biochemistry-included electrolytes, urea, creatinine, liver function test, lactate dehydrogenase. 
TABLE 2: Ann Arbor staging with Cotswold's modification

\begin{tabular}{|c|c|}
\hline Stage & Disease extent \\
\hline 1 & 1 node or a group of adjacent nodes \\
\hline $\begin{array}{l}\text { II } \\
\text { II -bulky }\end{array}$ & $\begin{array}{c}2 \text { or more nodal groups on the same side of the diaphragm } \\
\text { II as above with bulky* disease }\end{array}$ \\
\hline III & Nodes on both sides of the diaphragm \\
\hline IV & Additional non-contiguous extra lymphatic involvement \\
\hline A & Add to stage if there are no B-type symptoms \\
\hline B & $\begin{array}{l}\text { Add to stage if there are B symptoms ( } 10 \% \text { weight loss over } 6 \\
\text { months, fevers }>38 \text { degrees, recurrent drenching night sweats }\end{array}$ \\
\hline$E$ & $\begin{array}{c}\text { This is added to stage I or II disease only when there is direct } \\
\text { extension into an extra-nodal site**. }\end{array}$ \\
\hline
\end{tabular}

*Bulk is defined as a single nodal mass of at least $10 \mathrm{~cm}$, or greater than a third of the transthoracic diameter.

** Lymph nodes, spleen, Waldeyer's ring and thymus are considered nodal sites, with others defined as extra-nodal(3) 
TABLE 3: Staging and Risk Factors

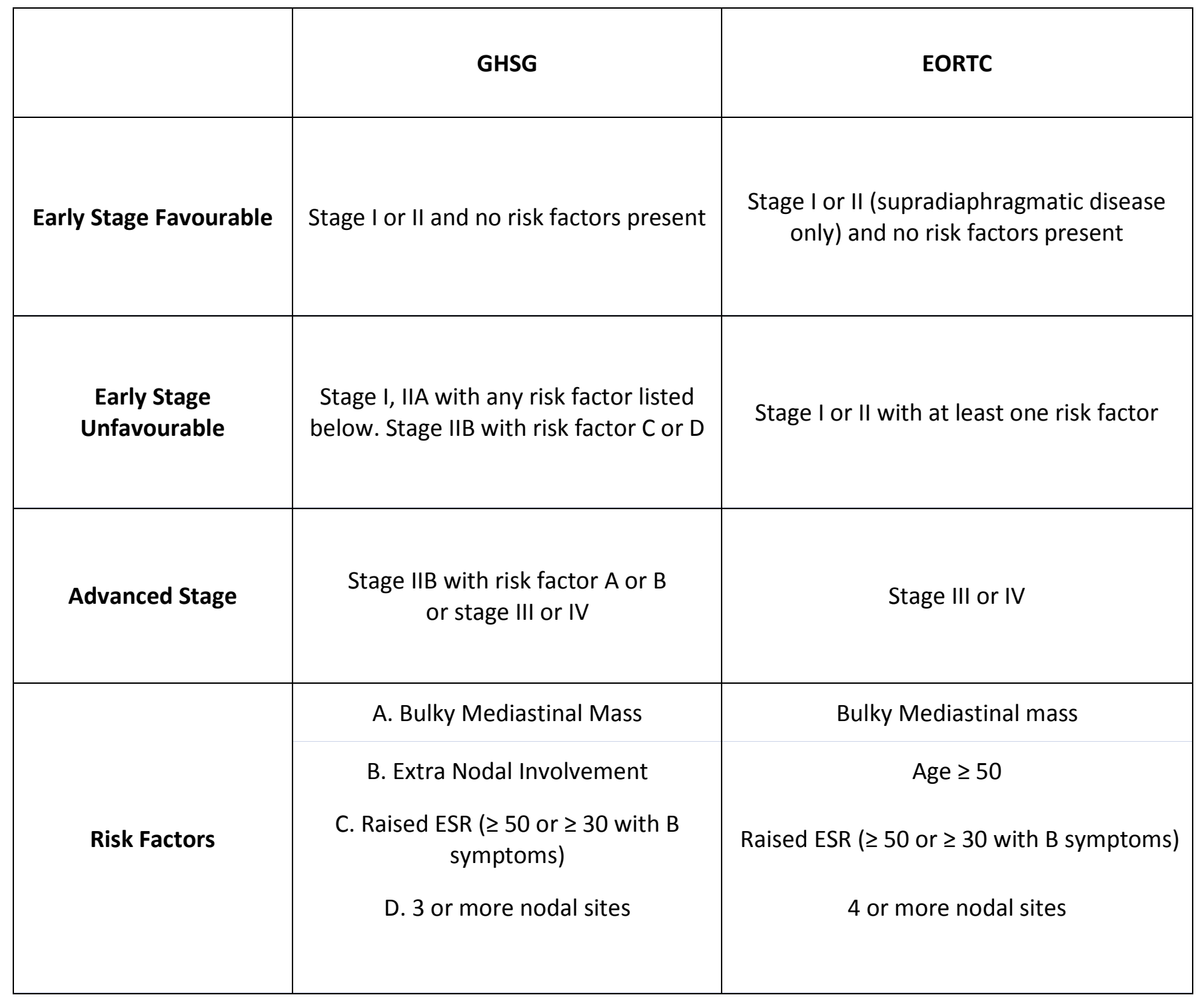


TABLE 4: International Prognostic Score - adverse risk factors

\begin{tabular}{|l|}
\hline Serum albumin, $<40 \mathrm{~g} / \mathrm{L}$ \\
\hline Haemoglobin, $<105 \mathrm{~g} / \mathrm{L}$ \\
\hline Male sex \\
\hline Stage IV disease \\
\hline Age, $\geq 45$ years \\
\hline White cell count, $\geq 15 \times 10^{9} / \mathrm{L}$ \\
\hline Lymphocyte count, $<0.6 \times 10^{9} / \mathrm{L}$ or $<8 \%$ of white cell count \\
\hline
\end{tabular}

Each factor present is given 1 point. Score is out of 7 
TABLE 5: Chemotherapy Regimens

\begin{tabular}{|c|c|c|c|}
\hline \multicolumn{4}{|c|}{ ABVD Regimen (1 Cycle is given every 28 days ) } \\
\hline Drug & Dose & Route & Day \\
\hline Doxorubicin & $25 \mathrm{mg} / \mathrm{m}^{2}$ & IV & 1 and 15 \\
\hline Vinblastine & $6 \mathrm{mg} / \mathrm{m}^{2}$ & IV & 1 and 15 \\
\hline Dacarbazine & $375 \mathrm{mg} / \mathrm{m}^{2}$ & IV & 1 and 15 \\
\hline Bleomycin & $10,000 \mathrm{IU} / \mathrm{m}^{2}$ & IV & 1 and 15 \\
\hline \multicolumn{4}{|c|}{ eBEACOPP Regimen (1 Cycle is given every 21 days) } \\
\hline Drug* & Dose & Route & Day \\
\hline Bleomycin & $10,000 \mathrm{lU} / \mathrm{m}^{2}$ & IV & 8 \\
\hline Etoposide & $200 \mathrm{mg} / \mathrm{m}^{2}$ & IV & 1 to 3 \\
\hline Doxorubicin & $35 \mathrm{mg} / \mathrm{m}^{2}$ & IV & 1 \\
\hline Cyclophosphamide & $1250 \mathrm{mg} / \mathrm{m}^{2}$ & IV & 1 \\
\hline Vincristine & $1.4 \mathrm{mg} / \mathrm{m}^{2}(\max 2 \mathrm{mg})$ & IV & 8 \\
\hline Prednisolone & $40 \mathrm{mg} / \mathrm{m}^{2}$ & PO & 1 to 14 \\
\hline Procarbazine & $100 \mathrm{mg} / \mathrm{m}^{2}$ & PO & 1 to 7 \\
\hline
\end{tabular}

*A corticosteroid pre-phase should be considered prior to commencing eBEACOPP in patients $>40$ years. 


\section{REFERENCES}

1. Steven Swerdlow EC, Nancy Harris, Elaine Jaffe. WHO Classification of Tumours of Haematopoietic and Lymphoid Tissues International Agency for Research on Cancer 2017.

2. Australian Institute of Health and Welfare Statistics ICD-10 C81 report 2019.

3. Cheson BD, Fisher RI, Barrington SF, Cavalli F, Schwartz LH, Zucca E, et al. Recommendations for initial evaluation, staging, and response assessment of Hodgkin and non-Hodgkin lymphoma: the Lugano classification. J Clin Oncol. 2014;32(27):3059-68.

4. Eghbali H, Raemaekers J, Carde P, Group EL. The EORTC strategy in the treatment of Hodgkin's lymphoma. Eur J Haematol Suppl. 2005(66):135-40.

5. Hasenclever D, Diehl V. A prognostic score for advanced Hodgkin's disease. International Prognostic Factors Project on Advanced Hodgkin's Disease. N Engl J Med. 1998;339(21):1506-14.

6. Fuchs M, Goergen H, Kobe C, Kuhnert G, Lohri A, Greil R, et al. Positron Emission Tomography-Guided Treatment in Early-Stage Favorable Hodgkin Lymphoma: Final Results of the International, Randomized Phase III HD16 Trial by the German Hodgkin Study Group. J Clin Oncol. 2019;37(31):2835-45.

7. Andre MPE, Girinsky T, Federico M, Reman O, Fortpied C, Gotti M, et al. Early Positron Emission Tomography Response-Adapted Treatment in Stage I and II Hodgkin Lymphoma: Final Results of the Randomized EORTC/LYSA/FIL H10 Trial. J Clin Oncol. 2017;35(16):1786-94.

8. Radford J, Illidge T, Counsell N, Hancock B, Pettengell R, Johnson P, et al. Results of a trial of PET-directed therapy for early-stage Hodgkin's lymphoma. N Engl J Med. 2015;372(17):1598-607.

9. Johnson P, Federico M, Kirkwood A, Fossa A, Berkahn L, Carella A, et al. Adapted Treatment Guided by Interim PET-CT Scan in Advanced Hodgkin's Lymphoma. N Engl J Med. 2016;374(25):241929.

10. Meyer RM, Gospodarowicz MK, Connors JM, Pearcey RG, Wells WA, Winter JN, et al. ABVD alone versus radiation-based therapy in limited-stage Hodgkin's lymphoma. N Engl J Med. 2012;366(5):399-408.

11. Campbell BA, Voss N, Pickles T, Morris J, Gascoyne RD, Savage KJ, et al. Involved-nodal radiation therapy as a component of combination therapy for limited-stage Hodgkin's lymphoma: a question of field size. J Clin Oncol. 2008;26(32):5170-4.

12. Wirth A, Mikhaeel NG, Aleman BMP, Pinnix CC, Constine LS, Ricardi U, et al. Involved Site Radiation Therapy in Adult Lymphomas: An Overview of International Lymphoma Radiation Oncology Group Guidelines. Int J Radiat Oncol Biol Phys. 2020;107(5):909-33.

13. Evens AM, Cilley J, Ortiz T, Gounder M, Hou N, Rademaker A, et al. G-CSF is not necessary to maintain over $99 \%$ dose-intensity with ABVD in the treatment of Hodgkin lymphoma: low toxicity and excellent outcomes in a 10-year analysis. Br J Haematol. 2007;137(6):545-52.

14. Wongso D, Fuchs M, Plutschow A, Klimm B, Sasse S, Hertenstein B, et al. Treatment-related mortality in patients with advanced-stage hodgkin lymphoma: an analysis of the german hodgkin study group. J Clin Oncol. 2013;31(22):2819-24.

15. Government N. Cancer Treatments Online. https://wwweviqorgau.

16. Klimm B, Goergen H, Fuchs M, von Tresckow B, Boll B, Meissner J, et al. Impact of risk factors on outcomes in early-stage Hodgkin's lymphoma: an analysis of international staging definitions. Ann Oncol. 2013;24(12):3070-6.

17. Herbst C, Rehan FA, Brillant C, Bohlius J, Skoetz N, Schulz H, et al. Combined modality treatment improves tumor control and overall survival in patients with early stage Hodgkin's lymphoma: a systematic review. Haematologica. 2010;95(3):494-500.

18. Ferme C, Eghbali H, Meerwaldt JH, Rieux C, Bosq J, Berger F, et al. Chemotherapy plus involved-field radiation in early-stage Hodgkin's disease. N Engl J Med. 2007;357(19):1916-27. 19. Engert A, Plutschow A, Eich HT, Lohri A, Dorken B, Borchmann P, et al. Reduced treatment intensity in patients with early-stage Hodgkin's lymphoma. N Engl J Med. 2010;363(7):640-52. 
20. von Tresckow B, Plutschow A, Fuchs M, Klimm B, Markova J, Lohri A, et al. Doseintensification in early unfavorable Hodgkin's lymphoma: final analysis of the German Hodgkin Study Group HD14 trial. J Clin Oncol. 2012;30(9):907-13.

21. S G, Plutschow A, Fuchs M, Markova J, Greil R, Topp M, et al. Dose-Intensification of Early Unfavorable Hodgkin Lymphoma: Long Term Follow Up of the German Hodgkin Study Group (GHSG) HD 14 Trial American Society of Hematology 2019.

22. Borchmann P, Plutschow A, Kobe C, Greil R, Meissner J, Topp MS, et al. PET-guided omission of radiotherapy in early-stage unfavourable Hodgkin lymphoma (GHSG HD17): a multicentre, openlabel, randomised, phase 3 trial. Lancet Oncol. 2021;22(2):223-34.

23. Canellos GP, Anderson JR, Propert KJ, Nissen N, Cooper MR, Henderson ES, et al. Chemotherapy of advanced Hodgkin's disease with MOPP, ABVD, or MOPP alternating with ABVD. N Engl J Med. 1992;327(21):1478-84.

24. Skoetz N, Will A, Monsef I, Brillant C, Engert A, von Tresckow B. Comparison of first-line chemotherapy including escalated BEACOPP versus chemotherapy including ABVD for people with early unfavourable or advanced stage Hodgkin lymphoma. Cochrane Database Syst Rev. 2017;5:CD007941.

25. Trotman J FA, Federico M, Stevens L, Kirkwood A, Clifton-Hadley L et al Response-adjusted therapy for advanced Hodgkin lymphoma (RATHL) trial: Longer follow up confirms efficacy of deescalation after a negative interim PET scan (CRUK/07/033. Hematologicla Oncology 2017;35:65-7. 26. Gallamini A, Hutchings M, Rigacci L, Specht L, Merli F, Hansen M, et al. Early interim 2[18F]fluoro-2-deoxy-D-glucose positron emission tomography is prognostically superior to international prognostic score in advanced-stage Hodgkin's lymphoma: a report from a joint ItalianDanish study. J Clin Oncol. 2007;25(24):3746-52.

27. Oki Y, Chuang H, Chasen B, Jessop A, Pan T, Fanale M, et al. The prognostic value of interim positron emission tomography scan in patients with classical Hodgkin lymphoma. Br J Haematol. 2014;165(1):112-6.

28. Borchmann P, Goergen H, Kobe C, Lohri A, Greil R, Eichenauer DA, et al. PET-guided treatment in patients with advanced-stage Hodgkin's lymphoma (HD18): final results of an openlabel, international, randomised phase 3 trial by the German Hodgkin Study Group. Lancet. 2018;390(10114):2790-802.

29. KreissI S, Goergen H, Kobe C, Lohri A, Greil R, Eichenauer D, et al., editors. PET Guided Treatment in Patients with Advanced Stage Hodkgin Lymphoma : Follow up Analysis of PET-2 Negative Patients in the HD18 Trial by the German Hodgkin Study Group. European Haematology Association 2020

30. Borchmann P. HD 21 for Advanced Stages - Treatment Optimization Trial in the First-Line Treatment of Advanced Stage Hodkin Lymphoma: Comparison of 4-6 cycles of escalated BEACOPP with 4-6 cycles of BrECADD. 2017 Version 5.0.

31. Casasnovas RO, Bouabdallah R, Brice P, Lazarovici J, Ghesquieres H, Stamatoullas A, et al. PET-adapted treatment for newly diagnosed advanced Hodgkin lymphoma (AHL2011): a randomised, multicentre, non-inferiority, phase 3 study. Lancet Oncol. 2019;20(2):202-15. 32. Connors JM, Radford JA. Brentuximab Vedotin for Stage III or IV Hodgkin's Lymphoma. N Engl J Med. 2018;378(16):1560-1.

33. Straus DJ, Długosz-Danecka M, Alekseev S, Illés Á, Picardi M, Lech-Maranda E, et al. Brentuximab vedotin with chemotherapy for stage 3/4 classical Hodgkin lymphoma: Three-year update of the ECHELON-1 study. DOI: 101200/JCO20193715_suppl7532 Journal of Clinical Oncology37, no 15_suppl(May 20, 2019)7532-7532 2019.

34. Engert A, Haverkamp H, Kobe C, Markova J, Renner C, Ho A, et al. Reduced-intensity chemotherapy and PET-guided radiotherapy in patients with advanced stage Hodgkin's lymphoma (HD15 trial): a randomised, open-label, phase 3 non-inferiority trial. Lancet. 2012;379(9828):1791-9. 35. Gallamini A, Rossi A, Patti C, Picardi M, Romano A, Cantonetti M, et al. Consolidation Radiotherapy Could Be Safely Omitted in Advanced Hodgkin Lymphoma With Large Nodal Mass in 
Complete Metabolic Response After ABVD: Final Analysis of the Randomized GITIL/FIL HD0607 Trial. J Clin Oncol. 2020;38(33):3905-13.

36. Boll B, Gorgen H. The treatment of older Hodgkin lymphoma patients. Br J Haematol. 2019;184(1):82-92.

37. Evens AM, Helenowski I, Ramsdale E, Nabhan C, Karmali R, Hanson B, et al. A retrospective multicenter analysis of elderly Hodgkin lymphoma: outcomes and prognostic factors in the modern era. Blood. 2012;119(3):692-5.

38. Boll B, Gorgen H, Fuchs M, Pluetschow A, Eich HT, Bargetzi MJ, et al. ABVD in older patients with early-stage Hodgkin lymphoma treated within the German Hodgkin Study Group HD10 and HD11 trials. J Clin Oncol. 2013;31(12):1522-9.

39. Boll B, Goergen H, Behringer K, Brockelmann PJ, Hitz F, Kerkhoff A, et al. Bleomycin in older early-stage favorable Hodgkin lymphoma patients: analysis of the German Hodgkin Study Group (GHSG) HD10 and HD13 trials. Blood. 2016;127(18):2189-92.

40. Behringer K, Goergen H, Hitz F, Zijlstra JM, Greil R, Markova J, et al. Omission of dacarbazine or bleomycin, or both, from the ABVD regimen in treatment of early-stage favourable Hodgkin's lymphoma (GHSG HD13): an open-label, randomised, non-inferiority trial. Lancet. 2015;385(9976):1418-27.

41. Boll B, Bredenfeld H, Gorgen H, Halbsguth T, Eich HT, Soekler M, et al. Phase 2 study of PVAG (prednisone, vinblastine, doxorubicin, gemcitabine) in elderly patients with early unfavorable or advanced stage Hodgkin lymphoma. Blood. 2011;118(24):6292-8.

42. Kolstad A, Nome O, Delabie J, Lauritzsen GF, Fossa A, Holte H. Standard CHOP-21 as first line therapy for elderly patients with Hodgkin's lymphoma. Leuk Lymphoma. 2007;48(3):570-6.

43. Favier O, Heutte N, Stamatoullas-Bastard A, Carde P, Van't Veer MB, Aleman BM, et al. Survival after Hodgkin lymphoma: causes of death and excess mortality in patients treated in 8 consecutive trials. Cancer. 2009;115(8):1680-91.

44. Patel CG, Michaelson E, Chen YH, Silver B, Marcus KJ, Stevenson MA, et al. Reduced Mortality Risk in the Recent Era in Early-Stage Hodgkin Lymphoma Patients Treated With Radiation Therapy With or Without Chemotherapy. Int J Radiat Oncol Biol Phys. 2018;100(2):498-506.

45. Aleman BM, van den Belt-Dusebout AW, Klokman WJ, Van't Veer MB, Bartelink H, van Leeuwen FE. Long-term cause-specific mortality of patients treated for Hodgkin's disease. J Clin Oncol. 2003;21(18):3431-9.

46. Bhatti $\mathrm{P}$, Veiga LH, Ronckers CM, Sigurdson AJ, Stovall M, Smith SA, et al. Risk of second primary thyroid cancer after radiotherapy for a childhood cancer in a large cohort study: an update from the childhood cancer survivor study. Radiat Res. 2010;174(6):741-52.

47. National Comprehensive Cancer Network. NCCN Clinical Practice Guidelines in Oncology: Hodgkin Lymphoma (Version 4.2021): National Comprehensive Cancer Network (NCCN); 2021 [updated 20 Apr 2021 cited 202119 Jul 2021 ].

https://www.nccn.org/professionals/physician gls/pdf/hodgkins.pdf]. Available from: https://www.nccn.org/professionals/physician gls/pdf/hodgkins.pdf.

48. Schaapveld M, Aleman BM, van Eggermond AM, Janus CP, Krol AD, van der Maazen RW, et al. Second Cancer Risk Up to 40 Years after Treatment for Hodgkin's Lymphoma. N Engl J Med. 2015;373(26):2499-511.

49. van Leeuwen FE, Ng AK. Long-term risk of second malignancy and cardiovascular disease after Hodgkin lymphoma treatment. Hematology Am Soc Hematol Educ Program. 2016;2016(1):32330.

50. Schonfeld SJ, Gilbert ES, Dores GM, Lynch CF, Hodgson DC, Hall P, et al. Acute myeloid leukemia following Hodgkin lymphoma: a population-based study of 35,511 patients. J Natl Cancer Inst. 2006;98(3):215-8.

51. Swerdlow AJ, Cooke R, Bates A, Cunningham D, Falk SJ, Gilson D, et al. Breast cancer risk after supradiaphragmatic radiotherapy for Hodgkin's lymphoma in England and Wales: a National Cohort Study. J Clin Oncol. 2012;30(22):2745-52. 
52. Krul IM, Opstal-van Winden AWJ, Aleman BMP, Janus CPM, van Eggermond AM, De Bruin ML, et al. Breast Cancer Risk After Radiation Therapy for Hodgkin Lymphoma: Influence of Gonadal Hormone Exposure. Int J Radiat Oncol Biol Phys. 2017;99(4):843-53.

53. Ng AK. Current survivorship recommendations for patients with Hodgkin lymphoma: focus on late effects. Blood. 2014;124(23):3373-9.

54. Inskip PD, Sigurdson AJ, Veiga L, Bhatti P, Ronckers C, Rajaraman P, et al. Radiation-Related New Primary Solid Cancers in the Childhood Cancer Survivor Study: Comparative Radiation Dose Response and Modification of Treatment Effects. Int J Radiat Oncol Biol Phys. 2016;94(4):800-7. 55. De Bruin ML, Sparidans J, van't Veer MB, Noordijk EM, Louwman MW, Zijlstra JM, et al. Breast cancer risk in female survivors of Hodgkin's lymphoma: lower risk after smaller radiation volumes. J Clin Oncol. 2009;27(26):4239-46.

56. Holmqvist AS, Chen Y, Berano Teh J, Sun C, Birch JM, van den Bos C, et al. Risk of solid subsequent malignant neoplasms after childhood Hodgkin lymphoma-Identification of high-risk populations to guide surveillance: A report from the Late Effects Study Group. Cancer. 2019;125(8):1373-83.

57. Kumar V, Garg M, Chandra AB, Mayorga VS, Ahmed S, Ailawadhi S. Trends in the Risks of Secondary Cancers in Patients With Hodgkin Lymphoma. Clin Lymphoma Myeloma Leuk. 2018;18(9):576-89 e1.

58. Conway JL, Connors JM, Tyldesley S, Savage KJ, Campbell BA, Zheng YY, et al. Secondary Breast Cancer Risk by Radiation Volume in Women With Hodgkin Lymphoma. Int J Radiat Oncol Biol Phys. 2017;97(1):35-41.

59. Eichenauer DA, Thielen I, Haverkamp H, Franklin J, Behringer K, Halbsguth T, et al. Therapyrelated acute myeloid leukemia and myelodysplastic syndromes in patients with Hodgkin lymphoma: a report from the German Hodgkin Study Group. Blood. 2014;123(11):1658-64.

60. Bhatt VR, Giri S, Verma V, Dahal S, Shah BK, Pathak R, et al. Secondary acute myeloid leukemia in survivors of Hodgkin lymphoma. Future Oncol. 2016;12(13):1565-75.

61. Chowdhry AK, Fung C, Chowdhry VK, Bergsma D, Dhakal S, Constine LS, et al. A populationbased study of prognosis and survival in patients with second primary thyroid cancer after Hodgkin lymphoma. Leuk Lymphoma. 2018;59(5):1180-7.

62. Wattson DA, Hunink MG, DiPiro PJ, Das P, Hodgson DC, Mauch PM, et al. Low-dose chest computed tomography for lung cancer screening among Hodgkin lymphoma survivors: a costeffectiveness analysis. Int J Radiat Oncol Biol Phys. 2014;90(2):344-53.

63. Stone CR, Mickle AT, Boyne DJ, Mohamed A, Rabi DM, Brenner DR, et al. Treatment for lymphoma and late cardiovascular disease risk: A systematic review and meta-analysis. Health Sci Rep. 2019;2(10):e135.

64. Zamorano JL, Lancellotti P, Rodriguez Munoz D, Aboyans V, Asteggiano R, Galderisi M, et al. 2016 ESC Position Paper on cancer treatments and cardiovascular toxicity developed under the auspices of the ESC Committee for Practice Guidelines: The Task Force for cancer treatments and cardiovascular toxicity of the European Society of Cardiology (ESC). Eur Heart J. 2016;37(36):2768801.

65. Jona A, Miltenyi Z, Ujj Z, Garai I, Szilasi M, Illes A. Late pulmonary complications of treating Hodgkin lymphoma: bleomycin-induced toxicity. Expert Opin Drug Saf. 2014;13(10):1291-7.

66. Inskip PD, Veiga LHS, Brenner AV, Sigurdson AJ, Ostroumova E, Chow EJ, et al. Hypothyroidism after Radiation Therapy for Childhood Cancer: A Report from the Childhood Cancer Survivor Study. Radiat Res. 2018;190(2):117-32.

67. Inskip PD, Veiga LHS, Brenner AV, Sigurdson AJ, Ostroumova E, Chow EJ, et al. Hyperthyroidism After Radiation Therapy for Childhood Cancer: A Report from the Childhood Cancer Survivor Study. Int J Radiat Oncol Biol Phys. 2019;104(2):415-24.

68. Behringer K, Mueller H, Goergen H, Thielen I, Eibl AD, Stumpf V, et al. Gonadal function and fertility in survivors after Hodgkin lymphoma treatment within the German Hodgkin Study Group HD13 to HD15 trials. J Clin Oncol. 2013;31(2):231-9. 
69. Mulder RL, Hudson MM, Bhatia S, Landier W, Levitt G, Constine LS, et al. Updated Breast Cancer Surveillance Recommendations for Female Survivors of Childhood, Adolescent, and Young Adult Cancer From the International Guideline Harmonization Group. J Clin Oncol. 2020;38(35):4194207.

70. International Guideline Harmonization Group. International Late Effects of Childhood Cancer Guideline Harmonization Group International Late Guideline Harmonization Group 2019 [http://www.ighg.org/].

71. Children's Oncology Group. Long-term Follow-up Guidelines for Survivors of Childhood, Adolescent and Young Adult Cancers Version 5.0: Children's Oncology Group; 2018 [updated October 2018. Available from:

http://www.survivorshipguidelines.org/pdf/2018/COG LTFU Guidelines v5.pdf. 72. Armenian SH, Hudson MM, Mulder RL, Chen MH, Constine LS, Dwyer M, et al.

Recommendations for cardiomyopathy surveillance for survivors of childhood cancer: a report from the International Late Effects of Childhood Cancer Guideline Harmonization Group. The Lancet Oncology. 2015;16(3):e123-e36.

73. NHMRC. NHMRC levels of evidence and grades for recommendations

for developers of guidelines 2009 [Available from:

https://www.nhmrc.gov.au/sites/default/files/images/NHMRC\%20Levels\%20and\%20Grades\%20(20 09).pdf. 